Research Article

\title{
Mechanical and Acoustic Emission Characteristics of Sandstone through Triaxial Unloading Test after Cyclic Freezing-Thawing Treatment
}

\author{
Xiaohui Ni $\left(\mathbb{D},{ }^{1,2}\right.$ Xiaomei Shen, ${ }^{1}$ and Zhende $\mathrm{Zhu}^{2}$ \\ ${ }^{1}$ College of Civil Engineering and Architecture, Jiaxing University, Jiaxing 314001, China \\ ${ }^{2}$ Geotechnical Research Institute of Hohai University, Hohai University, Nanjing 210098, China \\ Correspondence should be addressed to Xiaohui Ni; nixh2010@zjxu.edu.cn
}

Received 9 July 2019; Revised 8 September 2019; Accepted 2 December 2019; Published 24 January 2020

Academic Editor: Hossein Moayedi

Copyright (c) 2020 Xiaohui Ni et al. This is an open access article distributed under the Creative Commons Attribution License, which permits unrestricted use, distribution, and reproduction in any medium, provided the original work is properly cited.

\begin{abstract}
The dynamic failure behaviour of tunneling rock in the cold region where freezing-thawing frequently occurs is unclear. This study aimed to test and understand the damage characteristics of tunneling sandstone samples in the cold region via triaxial unloading test and acoustic emission (AE) technique. The sandstone samples were first subject to different cycles of freezing-thawing. Their stress-strain curves, deformation modulus, and the AE characteristics were then measured under triaxial unloading conditions and through the $\mathrm{AE}$ test. The results showed that the freezing-thawing treatment with less than 60 freezing-thawing cycles caused rather less damage compared to the triaxial unloading condition. For the samples subject to more severe freezing-thawing treatment, more cracks were produced. These cracks were not closed under small confining pressure during the triaxial test, causing weaker mechanical properties of samples. We also found that the freezing-thawing treatment had a significant deterioration on the mechanical properties of the sandstone samples when the number of freezing-thawing cycles exceeded a certain threshold (between 60 and 80 in this study). As the AE characteristics matched well with the key stages of the measured axial stress-strain curves and the deformation modulus that varied with the decreasing confining pressure, the AE characteristics can be potentially used to quantify the released energy of rock cracking and identify the critical damage phases during the tunneling engineering process.
\end{abstract}

\section{Introduction}

During the excavation of highly stressed rock mass, the rock mass is often in a state of unilateral or double-side unloading. The unloading condition causes the stress redistribution and disturbance, energy release, and rock damage in the forms of spalling and strain burst [1-3]. The stability of rock structures and the mechanical properties of rock masses could be therefore impacted and altered [4]. As a result, the damage characteristics of rock (e.g., cracking and failure modes) in the excavation zone induced by the tunnel boring machine or blasting have been extensively investigated through experimental and numerical studies [5-9].

Recently, many infrastructure engineering projects such as tunneling have been carried out in the freezing-thawing zones in China and Asian countries as a result of the implementation of the Belt and Road Initiative. In cold region, the rock is under freeze-thaw cycles, and its internal pores are subject to high pore pressure, causing damage on the microstructure of pores and then on the whole mechanical properties of rocks [10-12]. Besides, the mechanical properties of the rocks under unloading state are rather different from those under loading state $[2,13,14]$, and it is thus necessary to study the physical characteristics of the rock under unloading condition [3], particularly those in the cold region. However, most existing studies [3, 4, 13, 15] focus on the understanding of dynamic rock or concrete failure characteristics through unloading tests without experiencing freeze-thaw cycles. For example, a true triaxial test cell was designed by Zhu et al. [15] to simulate the excavation process by unloading the confining pressure on 
one surface of the prismatic mortar samples. Their results showed that the splitting fracture exhibited an arc shape with the fracture contour directed towards the unloaded surface instead of a parallel shape to the unloaded surface. The numerical simulation was also carried out by researchers to understand the failure behaviour under unloading tests. For example, Manouchehrian and Cai [13] simulated the unstable rock failures under unloading conditions by the ABAQUS3D explicit code and found that rock failure was more violent with the softer loading system. But the interface contact between the loading platens and the rock sample was assumed to be frictionless, and the end friction effect on the damage behaviors was ignored.

Most tunneling projects are implemented in areas with a normal temperature range. This is probably why there are only a few studies that present the damage characteristics of rocks subject to freezing-thawing cycles through unloading tests. For example, Yu et al. [16] investigated the dynamic mechanical properties of sandstone after freezing-thawing cycles under triaxial confining pressure unloading, while the mechanism was not thoroughly explored by analyzing the internal structure of sandstone samples. Since the unloading-induced stress complicates the pore size and its distribution as well as the microstructure and microcracks of rocks under freeze-thaw cycles [4], the rock mechanics and failure characteristics could be significantly different under unloading conditions and are worth for further investigation.

An acoustic wave would be produced in the form of released energy from rock mass while cracking and rock burst along the unloading face of excavation $[1-3,17,18]$. This acoustic emission (AE) is a phenomenon that occurs when strain energy is released in the form of elastic waves during the failure process of material [19]. An AE device can thus be utilized to monitor the damage and cracking of rock materials $[20,21]$. Given the low cost, easy, and efficient advantages compared to other in situ stress test methods, the AE technique has been broadly applied to test the rock mechanics under true-triaxial conditions by analyzing the AE characteristics for the understanding of mechanical properties in the process of rock failure [1, 14, 22-24]. Generally, most studies focus on the analysis of the released energy (i.e., AE energy) and AE event counts or counting rate [19, 25-27]. For example, He et al. [14] investigated the dynamic damage process and characteristics of limestone under true-triaxial unloading conditions by conducting frequency-spectra analysis for the full-wave AE data. The AE quickly accumulated released energy from the unloading state of the rock.

In this paper, we aimed to characterize and understand the damage behaviors of tunneling sandstones in cold regions. The tunnel sandstone samples were collected in the Altay region of Xinjiang province, China; their mechanical and $\mathrm{AE}$ characteristics after the freezing-thawing cycles under triaxial unloading conditions (i.e., compression loading and confining pressure unloading test) were than investigated. Note that Altay region of Xinjiang province is a representative area where freezing-thawing occurs in China. The samples were first subjected to freezing-thawing and then triaxial unloading treatment, during which the acoustic emission test was conducted. The microscopic structures of the sample at different treatment stages were imaged by using the scanning electron microscope (SEM). It was shown that the $\mathrm{AE}$ characteristics were correlated to the damage behaviour, revealing the damage propagation behaviour of excavation rock masses in the cold region. The practical implication of this study is also discussed, mainly regarding the application of AE technique in identifying the tunneling rock damage.

\section{Materials and Methods}

2.1. Experimental Approach. The tunneling sandstone samples were prepared and placed in the SEM chamber to collect the first group of SEM images and analyze the microstructure of sandstone samples without being damaged. Subsequently, the freezing-thawing tests were then conducted, followed by the second SEM imaging operation to collect the second group of SEM images and characterize the damage caused by freezing-thawing cycles. The unloading test with axial compression and unloading confining pressure was performed together with the AE test to characterize the released energy while cracking. After the AE test was completed, the third group of SEM images was collected through another SEM imaging process to understand the damage caused by the unloading test (Figure 1). By implementing the above testing design, the damage caused by the freezing-thawing treatment can be recognized from the difference of cracking characteristics analyzed in the first and the second groups of SEM images; the damage caused by the unloading condition can be recognized from the difference of cracking characteristics analyzed in the second and the third groups of SEM images. A single-lens reflex camera was also used to photograph the exterior surface of samples under different freezing-thawing cycles and those after triaxial unloading test for the characterization of cracks.

2.2. Sample Preparation. The rock samples used in this study were obtained from the excavation face of a tunnel in Altay region, Xinjiang province, China. All samples are from one visually homogeneous sandstone zone, with slight difference caused by sampling process. Through the phase analysis, it was observed that they are mainly composed of quartz (47.26\%), feldspar (18.32\%), and mica (13.45\%). The sandstone samples were off-white with a little argillaceous inclusion. The grain size of the sample was in a medium range.

The diameter and the height of the standard cylindrical sample are $50 \mathrm{~mm}$ and $100 \mathrm{~mm}$, respectively. Note that this dimension of the sample was designed by following the ISRM suggested method for the complete stress-strain curve for intact rock in uniaxial compression [28], and it can also be found in other studies $[25,29]$. The sandstones were cut to meet this standard with end faces with $\pm 0.05 \mathrm{~mm}$ parallelism and $\pm 0.02 \mathrm{~mm}$ flatness. The samples were manually grinded to this standard size in order to minimize the damage from hydraulic cutting. The samples with cracks and joints were removed. The remaining samples with consistent 


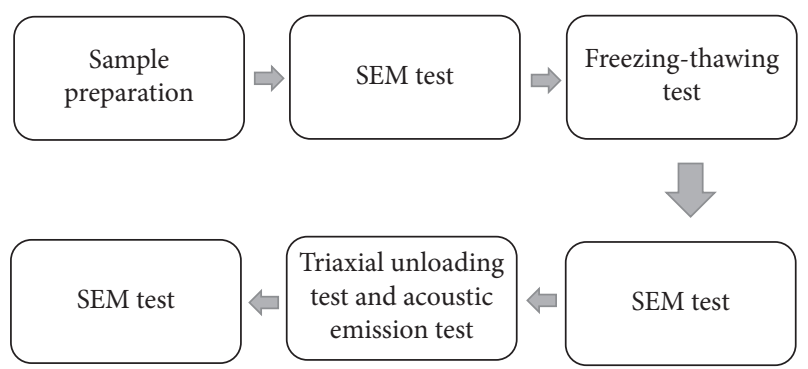

FIGURE 1: The experiment process including sample preparation, SEM tests, freezing-thawing treatment, and triaxial unloading test with $\mathrm{AE}$ test.

mechanical properties were analyzed through the longitudinal wave velocities in the samples. The average value of longitudinal wave velocity was $3321 \mathrm{~m} / \mathrm{s}$.

\subsection{Freezing-Thawing Test. An ultralow-temperature freezer} (DW-60W60) with a minimum temperature of $-65^{\circ} \mathrm{C}$ and accuracy of $0.1^{\circ} \mathrm{C}$ and a thermostatic drying oven (101A-1) were used to conduct the freezing-thawing cycles. This freezing-thawing test and the following triaxial unloading test were performed according to the code for rock tests of hydroelectric and water conservancy engineering [30].

The temperature, the period, and the number of freezing-thawing cycles are crucial parameters in the cyclic freezing-thawing test. The highest temperature and the lowest temperature of freezing-thawing cycles were, respectively, set to $20^{\circ} \mathrm{C}$ and $-30^{\circ} \mathrm{C}$ in view of the temperature history recorded in Altai of Xinjiang province from 2011 to 2013 (Figure 2). The temperature of a water tank was set to be $20^{\circ} \mathrm{C}$. The samples were first placed in this water tank. After pumping the air in the water tank for $2 \mathrm{~h}$, distilled water was injected [16]. When no bubbles were observed, the evacuation can be stopped. The samples were then immersed in the water tank for $48 \mathrm{~h}$. After that, the samples were put into the ultralow-temperature freezer at $-30^{\circ} \mathrm{C}$ for nine hours and then into the water with the temperature of $20 \pm 2^{\circ} \mathrm{C}$ for $5 \mathrm{~h}$. This step completed a freezing-thawing cycle with a total period of $14 \mathrm{~h}$. Five groups of samples were produced by performing $0,20,40,60$, and 80 times of freezing-thawing on them.

2.4. Triaxial Unloading Test. Figure 3 shows the MTS 815 rock mechanics test system used in the triaxial unloading test. The test system was with the maximum axial load of $4600 \mathrm{kN}$ and the maximum confining pressure of $140 \mathrm{MPa}$, located in the State Key Laboratory for Geomechanics and Deep Underground Engineering, China University of Mining and Technology. Following the freezing-thawing treatment, the triaxial unloading test was conducted at a room temperature of $23^{\circ} \mathrm{C}$. The test system was composed of the loading system, the servo control system, and the confining pressure system. The control method of loading included load control, axial displacement control, and circumferential displacement control. Based on the hydrostatic pressure condition (the axial pressure equals to the confining

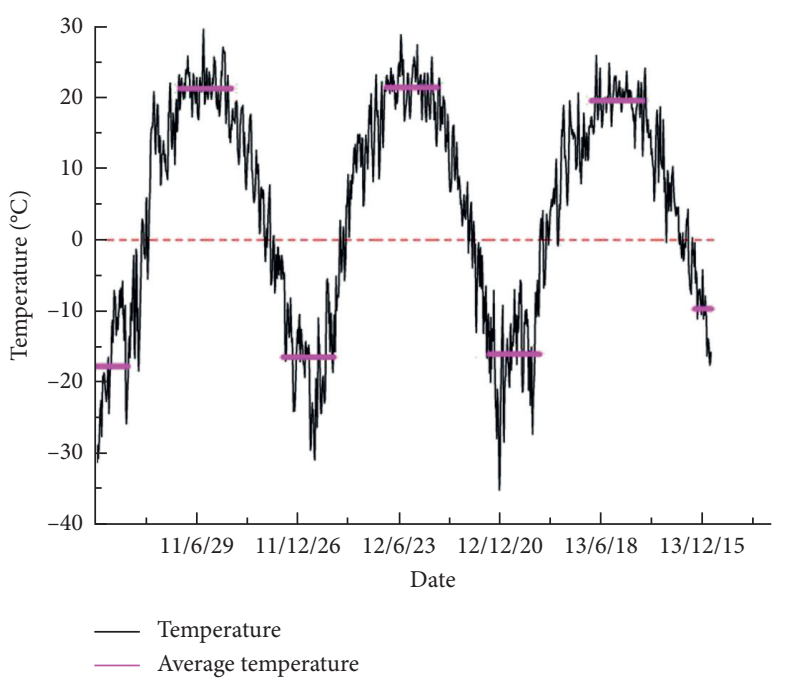

FIgURE 2: The temperature variation in Altai of Xinjiang from 2011 to 2013 .

pressure), we applied $14 \mathrm{MPa}$ of the hydrostatic pressure to the sample by controlling the stress rate. The axial pressure was gradually increased to about $75 \mathrm{MPa}$ at a displacement rate of $0.004 \mathrm{~mm} / \mathrm{s}$ but with the constant confining pressure $(14 \mathrm{MPa})$. During the unloading process, the confining pressure was then decreased at a rate of $0.05 \mathrm{MPa} / \mathrm{s}$; this could produce damages in the samples.

2.5. AE Test. Under the triaxial unloading condition, the $\mathrm{AE}$ test was conducted by using an advanced AE system (PCI-2); that is to say, the $\mathrm{AE}$ test and the unloading test were conducted simultaneously. The samples were placed vertically in the system. Figure 4 shows the arrangement of four AE sensors on the sample exterior surface. Sensors 1 and 2 were placed symmetrically with a distance of $10 \mathrm{~mm}$ from the top of the sample. Sensors 3 and 4 were located symmetrically with a distance of $10 \mathrm{~mm}$ from the bottom. The connecting line of the sensors 1 and 2 in the same cross section was parallel to that of sensor 3 and sensor 4 . Sensors 5 and 6 were placed in the middle of the sample. The connecting line of Sensors 5 and 6 was vertical to that of Sensors 1 and 2. This arrangement was made to ensure that the released energy was detected by the sensors while cracking. The accumulated AE energy during cracking and the counting rate were recorded. The "counting rate" means the number of cracking events that exceed the threshold per second. This threshold value was set to 40 decibels according to the background noise in the lab.

2.6. Scanning Electron Microscope Test. At least six representative disk samples $(10 \mathrm{~mm} \times 10 \mathrm{~mm} \times 5 \mathrm{~mm})$ were sectioned from different locations of each column sample. The disks were first cleaned, dried, and gilded and then placed on the Quante-250 SEM chamber for taking images. Figure 5 shows a photo of the Quante-250 SEM in the lab. Each section was scanned row by row to avoid the repetition or the omission of key sample position. Most of SEM images 


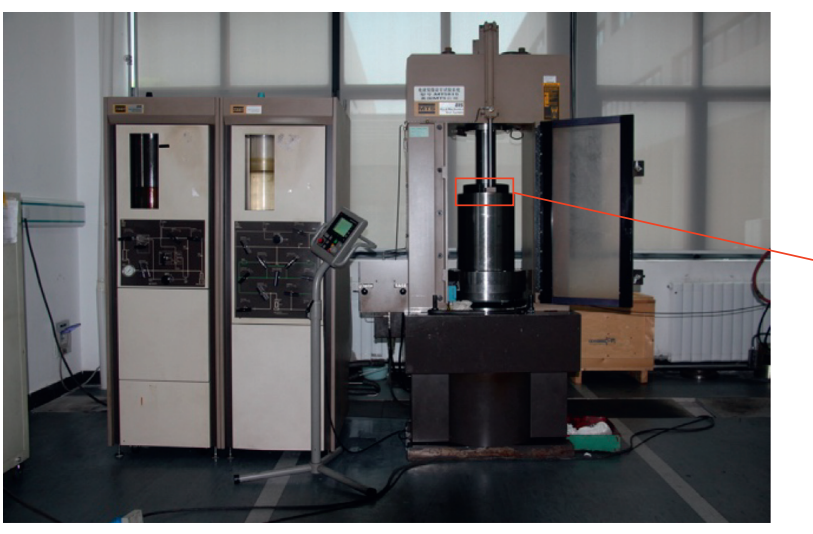

(a)

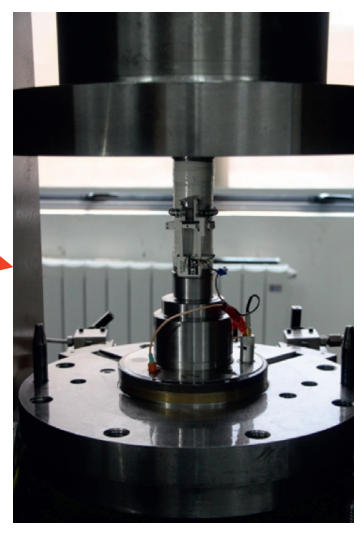

(b)

Figure 3: Photos of the MTS815 rock mechanics test system and sample under loading: (a) whole MTS815 test system; (b) sample under loading.

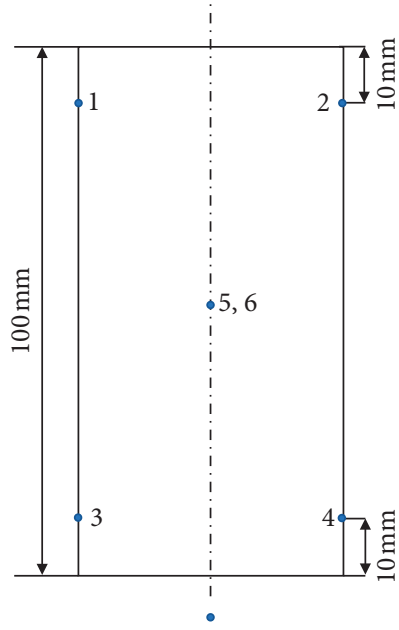

(a)

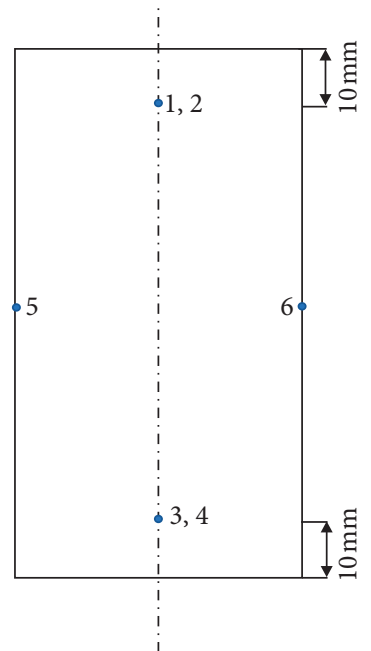

(b)

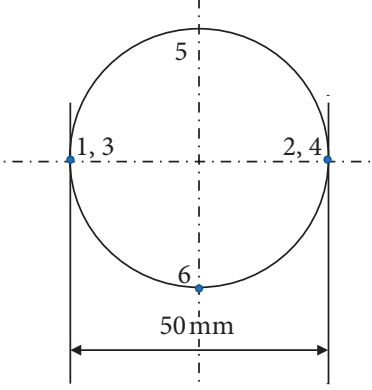

(c)

Figure 4: The AE arrangement of AE sensors on samples: (a) front view; (b) side view; (c) top view.

were taken with $\times 1000$ magnification, and some of them were taken with $\times 500$ and $\times 2000$ magnification. The sample damage characteristics at the microscopic scale were then analyzed through these SEM images. Note that there are three imaging processes that were carried out as described in Section 2.1.

\section{Experimental Results and Discussion}

3.1. Cracking Characteristics. Figure 6 presents the overall damage characteristics of representative sandstone samples after different freezing-thawing cycles and their corresponding damage characteristics after the compression loading and confining pressure unloading test at the macroscale. The results showed that the freezing-thawing treatment had a much less damage to the samples compared to the triaxial unloading condition. The cracking was first observed on the exterior surface of the sample when it was subjected to 40 freezing-thawing cycles (Figure 6(c)). For the sample under 80 freezing-thawing cycle (Figure 6(e)), its exterior surface was cracked and spalling occurred. However, severe through cracking (cracks that develop through the whole sample) was observed for samples under triaxial unloading test and without freezing-thawing treatment, as shown in Figure 6(f). Further examination on the comparison between Figures 6(a)-6(e) shows that the sandstone sample experienced nonuniform deformations. This may be due to the fact that different exterior surfaces of the sample were subject to different thermal or pressure gradients that were caused by freezing-thawing treatment. For example, the sample's bottom surface was enclosed by the ground and was thus under less thermal gradients caused by the freezing cycles compared to the sample's top surface, which was exposed to freezing-thawing treatments. The initial water content of the sample could also be nonuniform as the external surface was drier than the internal structures [31]. This could also contribute the nonuniform deformation of sandstone samples.

After the triaxial unloading test, the fracture of all the samples appeared as shear failure. That is, the main fracture 


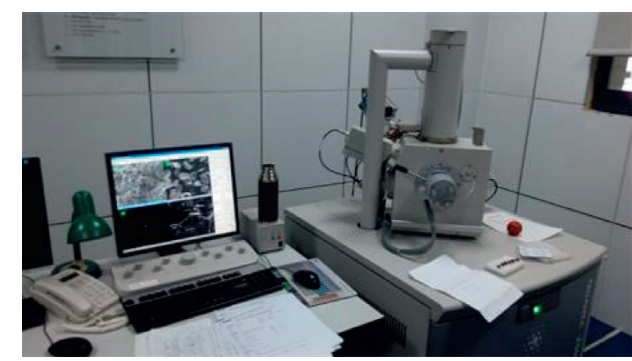

Figure 5: The Quante-250 scanning electron microscope.

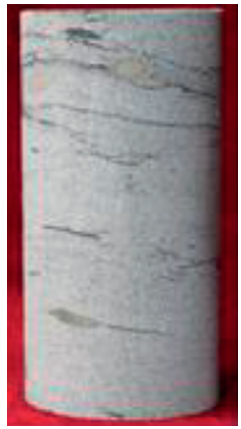

(a)

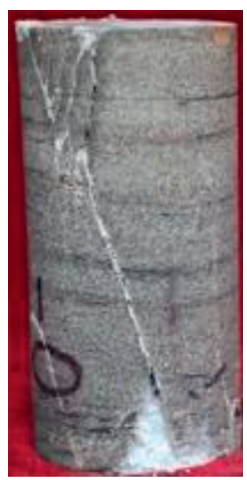

(f)

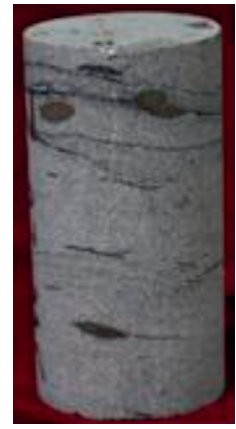

(b)

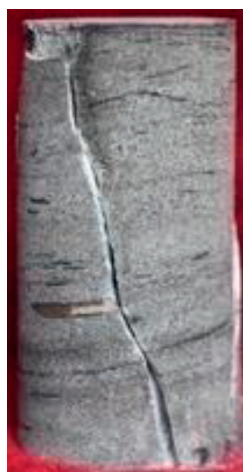

(g)

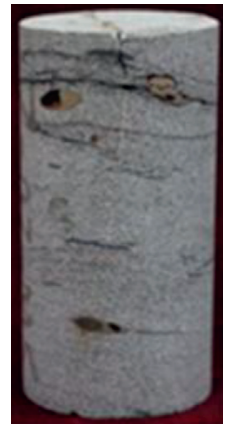

(c)

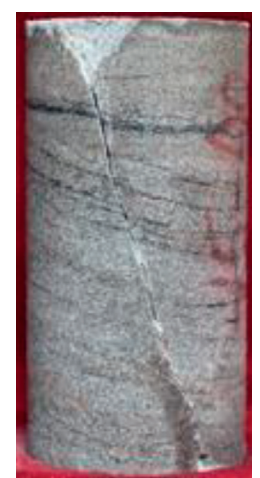

(h)

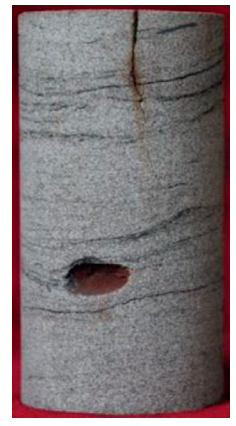

(d)

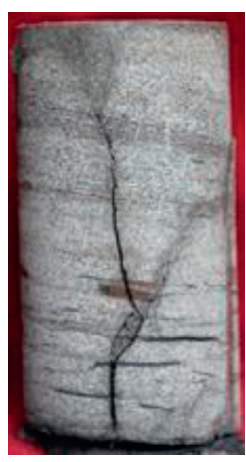

(i)

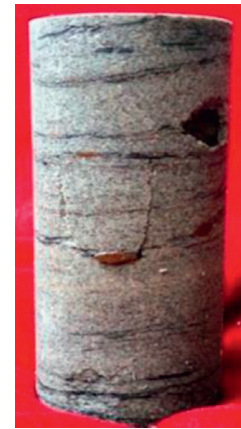

(e)

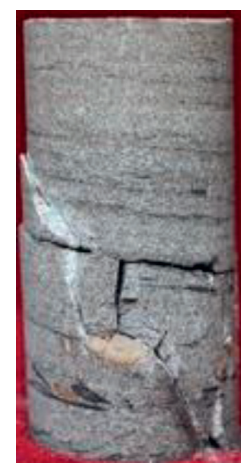

(j)

FiguRe 6: The exterior surfaces of sandstone samples after different freezing-thawing cycles (a) 0, (b) 20, (c) 40, (d) 60, (e) 80, and the corresponding ones after triaxial unloading test $(\mathrm{f}-\mathrm{j})$.

would cut through both the end faces of the sample, forming a section intersected with the central axiality. The end faces were grinded to ensure their good flatness; thus, the end friction effect on the damage behaviors could be ignored in this study. This shear behaviour is expected as the unloading leads the shear stress to increase and the shear strength to decrease, potentially causing the shear slipping and failure [29]. With the increasing number of freezing-thawing cycles, the main failure became more severe, and spalling occurred at the end faces of the sample. The internal microcracks could have formed into macrocracks. This inference was verified by the SEM image analysis (Figure 7). Additional macrocracks that propagated from the main fracture surface were also observed. The above observations are consistent with others' studies such as Yu et al. [16] and Wang et al. [32].
The above observations focus on the external surfaces and macrocracks, which generally indicate the moderate influence of freezing-thawing and significant influence of triaxial unloading treatment on the damage state of sandstone samples. To further understand their influence, we then examine the internal microstructure of samples at various representative stages.

Figure 7 shows the representative SEM images of the internal morphologies of sandstone samples before freezingthawing treatment and after 40 freezing-thawing cycles as well as after triaxial unloading tests for the same sample. Note that the 40 freezing-thawing cycles were a critical freezing-thawing treatment as shown in Figure 6(c), and it was thus chosen for SEM imaging. As expected in Figure 7(a), the sample without being subject to freezing-thawing treatment presents dense and continuous internal morphologies, while the freezing- 


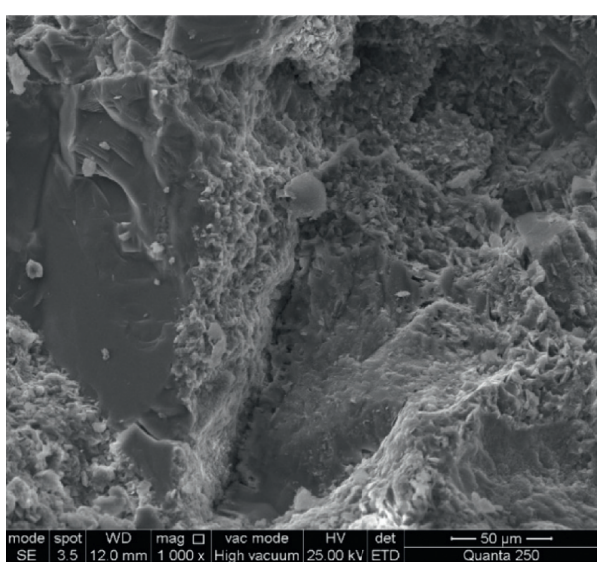

(a)

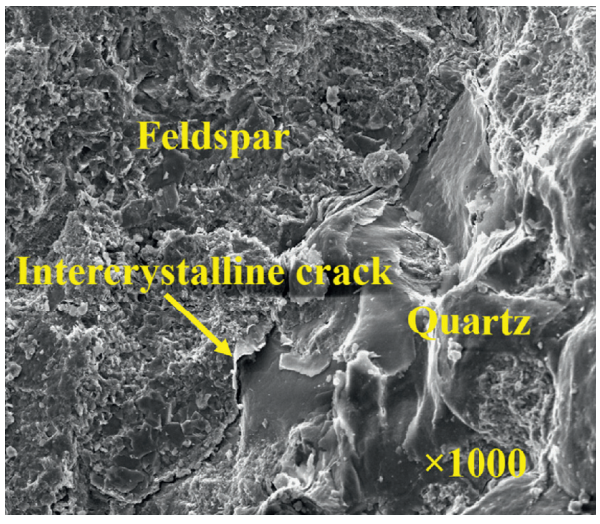

(c)

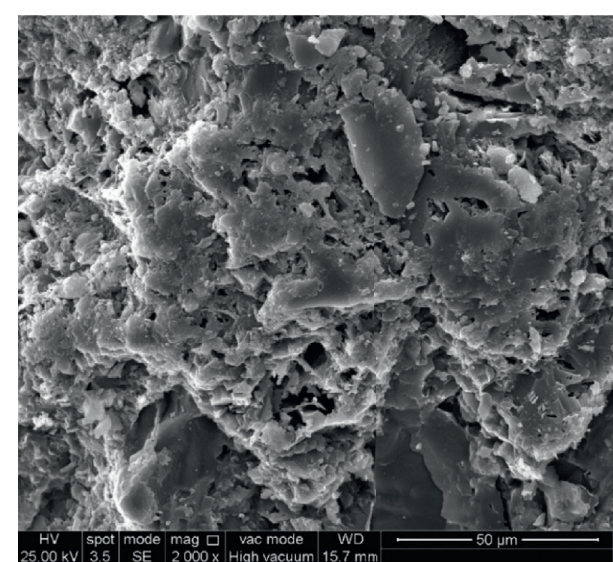

(b)

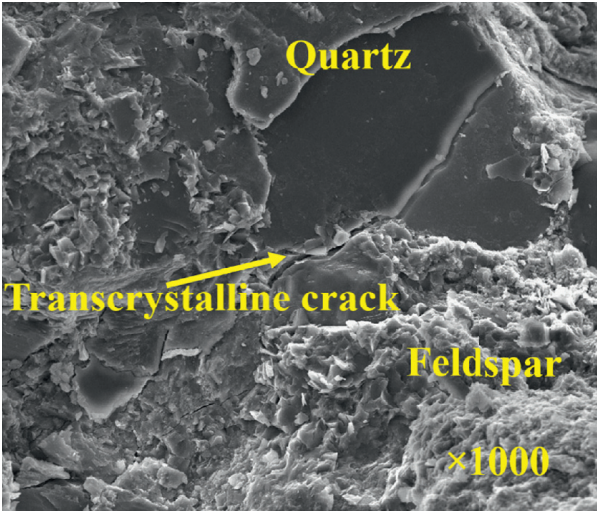

(d)

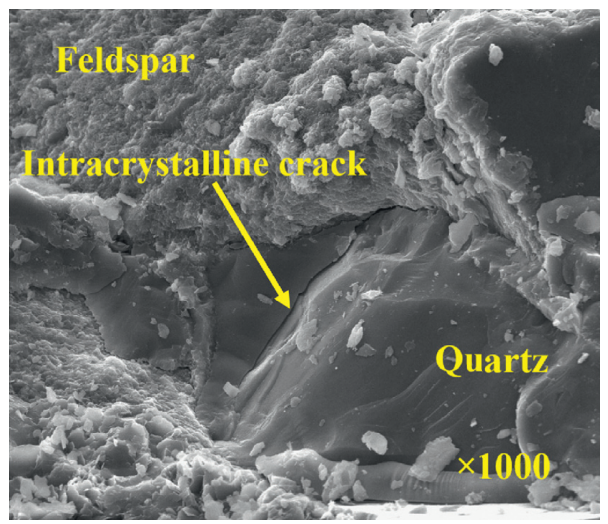

(e)

FiguRE 7: Representative SEM images of sandstone morphologies in microscale: (a) before freezing-thawing treatment; (b) after 40 freezingthawing cycles; (c) after triaxial unloading test with typical intercrystalline crack; (d) after triaxial unloading test with typical transcrystalline crack; (e) after triaxial unloading test with typical intracrystalline crack.

thawing treatments after 40 cycles (Figure 7(b)) caused severe damage to the microstructure of samples. The pores became larger and more connected; cavities and microcracks were also observed. This result indicates the pores collapsed under high pore pressure caused by the cyclic freezing-thawing cycles [10-12]. There is only one macrocrack appearing on the exterior surface of the sample (Figure 6(c)), indicating that most internal microcracks are still not interconnected and the damage is not severe. With further triaxial unloading operation, severe cracking was found, as shown in Figures $7(\mathrm{c})-7(\mathrm{e})$. As a result, the mechanical properties of sample significantly decreased, as shown in Figure 8. Also, the comparison between the freezing-thawing and triaxial unloading treatment shows that the former mainly causes the damage to the internal pore structure, while the latter could subsequently induce severe cracking. There are three types of the observed cracks. They are as follows: intercrystalline crack that occurred along the boundary of mineral crystals, 


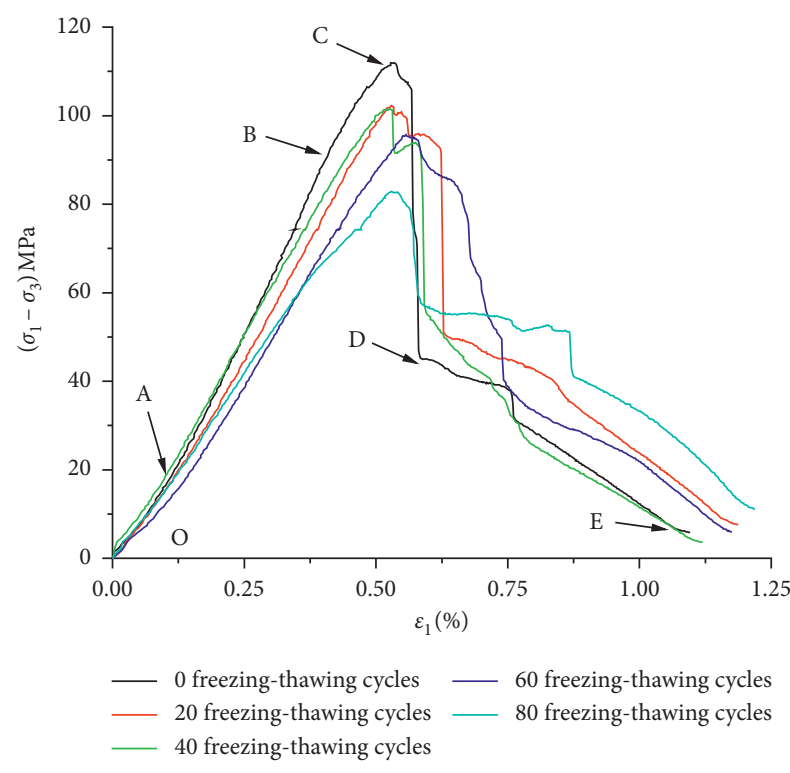

FIgURE 8: The axial stress-strain curves of the sandstone samples after freezing-thawing cycles.

transcrystalline crack that propagated through the mineral crystals, and intracrystalline crack that occurred inside the mineral crystals. These three types of cracks are expected as the resistance of quartz to cracking is different at different regions of the sample, causing the different propagation paths of cracks.

3.2. Stress-Strain Curves. Figure 8 shows the axial stressstrain curves of different groups of sandstone samples under different freezing-thawing cycles during the increase of axial compression load.

The variation trends of the axial stress-strain curves after different freezing-thawing cycles were generally similar. Thus, six points (O, A, B, C, D, and E) are marked out on the axial stress-strain curve for zero freezing-thawing cycle in Figure 8. These points divide the curves into five stages, which are the lower-convex increasing stage (OA), the linear increasing stage $(\mathrm{AB})$, the upper-convex increasing stage (BC), the dropping failure stage (CD), and the deformation stage after failure (DE). The details of these five stages are as follows.

More cycles of freezing-thawing would lead to more cracks and large pores inside the samples, particularly after 40 freezing-thawing cycles (Figures 6(d), 6(e), and 7(b)). At the initial stage, the axial compression slightly increased while the confining pressure was still high (OA stage in Figure 8), and most microcracks could be compacted and closed. Thus, the freezing-thawing treatment had a minor influence on the stress-strain behaviors when the confining pressure was still high. This inhibitory effect of confining pressure on crack expansion was also reported by other researchers such as Li et al. [21] and Wu et al. [33]. The latter research experimentally showed the microcracks partially closed under confining pressure using fluorescence microscopy, but the total porosity was not significantly affected.
With higher axial compression load and more confining pressure released, the gradient of the $A B$ stage curves decreased with the increasing freezing-thawing cycles, i.e., the freezing-thawing extent. This result was expected as less number of microcracks was closed under decreasing confining pressure. The existing cracks could deteriorate the sandstone mechanical capacity including the elastic modulus [34].

The samples reached the yielding state during the BC segment. The measured peak strength of the samples decreased significantly as the number of freezing-thawing cycles increased. For example, the peak strength decreased by around $27 \%$ when the freezing-thawing cycle number increased from zero to 80 . This result occurred with higher axial compression, and further confining pressure released when more interconnected cracks appeared. Note that the peak strength of the cracked material has been frequently measured for the characterization of the stress-strain curve [35].

In the next stage, i.e., CD stage, due to the significant cracking and the development of major fracture, the axial stress decreased significantly with minimal increase of strain. It is interesting to observe that the decreasing range was reduced with more freezing-thawing cycles. This is because the cracking occurred earlier for samples under more severe freezing-thawing treatment, resulting in an earlier release of internal energy. The remaining internal energy was thus less for those samples with more severe freezing-thawing treatment, causing short dropping range of peak strength.

With further unloading of confining pressure, more cracks occurred and were connected to form the through crack, and more pores could collapse. Meanwhile, particles from the cementing materials could be spalled or broken due to the excessive pore pressure. These particles could be rearranged to form a new structure element to assist the stress. This is probably why the stress-strain curve became much flatter compared to that in the CD stage.

Figure 9 presents the variation of the deformation modulus with the decreasing confining pressure. As expected, the deformation modulus decreased with freezingthawing cycles. When the confining pressure was released before around $10 \mathrm{MPa}$, the initial damage due to the 20 freezing-thawing cycles significantly decreased the deformation modulus. With the freezing-thawing cycle increased up to 40 and 60, the deformation modulus decreased further but with a slower decreasing rate. However, the deformation modulus started to significantly drop when the freezingthawing cycle increased to 80 . When the confining pressure was decreased to less than $10 \mathrm{MPa}$, severe damage occurred in all the samples regardless of freezing-thawing cycle times; thus, the deformation modulus values of all the samples were rather low without much difference between them.

Four points are marked out in Figure 9 to describe the key stages of deformation modulus variations. These points divided the curves into three distinguishable stages, which are the nonlinear increasing stage $(\mathrm{AB})$, the nonlinear decreasing stage $(B C)$, and the dropping stage $(C D)$. In the $A B$ stage, the deformation modulus slightly increased with the decreasing confining pressure. This could be because the 


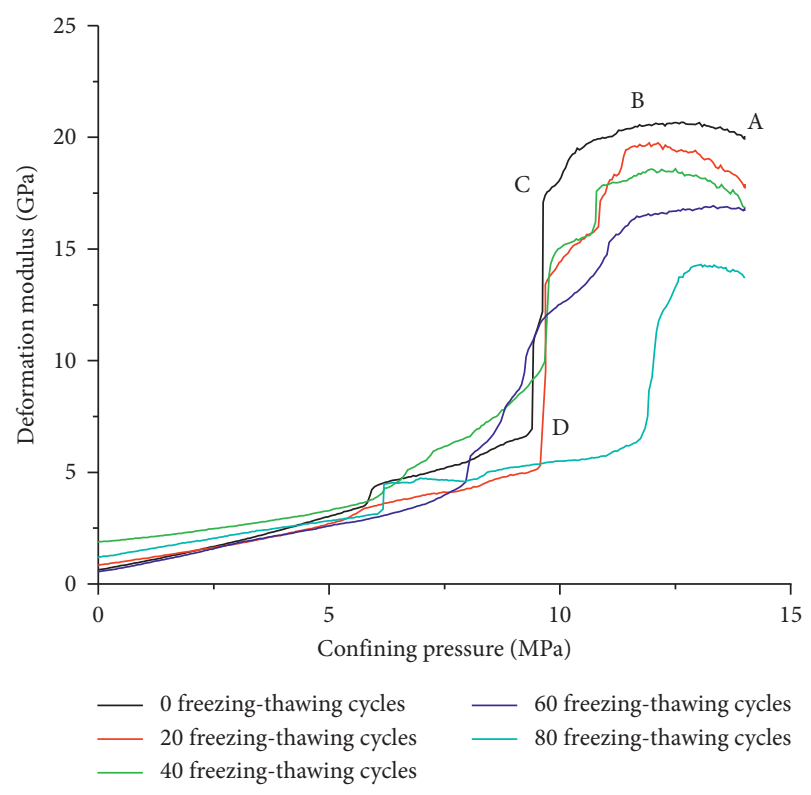

FIgURE 9: The relationship between the deformation modulus and the confining pressure under freezing-thawing cycles.

initial increase of axial compression and the decrease of confining pressure jointly readjusted the stress-strain state to produce the higher deformation modulus. Afterwards, the damage caused by the unloading outweighed the above strengthening effect, and the deformation modulus started to decrease with the decreasing confining pressure, as shown in $\mathrm{BC}$ and $\mathrm{CD}$ stages. This is also presented by other researchers such as Wang et al. [32].

\section{Results of AE Test}

4.1. Typical $A E$ Characteristics. Figure 10 shows the variation of two $\mathrm{AE}$ parameters (i.e., counting rate and the accumulated AE energy) during the whole period of the unloading test on the samples under $0,20,40,60$, and 80 freezing-thawing cycles. This period was divided into four distinguishable stages ( $\mathrm{AB}, \mathrm{BC}, \mathrm{CD}$, and $\mathrm{DE}$ stages) by the vertical dashed lines $\mathrm{B}, \mathrm{C}, \mathrm{D}$, and $\mathrm{E}$. As the $\mathrm{AE}$ characteristic patterns for different samples under different freezingthawing cycles are similar, a typical pattern for samples under 20 freezing-thawing cycles (Figure 10(b)) was described to understand how the $\mathrm{AE}$ characteristics varied during the whole period of the triaxial unloading test.

In the linear increasing stage $(\mathrm{AB})$ from the test beginning to $50 \mathrm{~s}$, the axial load was low, and its contribution to producing cracking was negligible. Also, the large confining pressure could restrict the cracking. Consequently, $\mathrm{AE}$ events barely happened in the samples, indicating that no cracking events occurred in this stage. This is consistent with the observation in the OA stage in Figure 8. With the axial loading increasing, its contribution effect on cracking became stronger than the confining pressure's restriction effect on cracking. The growth of microcracks was slightly increased, but the microcracks were still limited by the confining pressure. This attributed to the increase of the counting rate value and the minor increase of the accumulated AE energy. For example, the value of the counting rate of the samples after 20 cycles of freezing-thawing exceeded $20 \times 103 / \mathrm{s}$ for ten times, and the accumulated AE energy was increased to about $1.9 \times 106$ in the period of $50 \mathrm{~s}$ to the line B (Figure 10(b)).

In the upper-convex increasing stage $(\mathrm{BC})$, the number of microcracks increased quickly due to the further increase of axial compression and the unloading of confining pressure. This increase led to the increases in the number of cracking events (i.e., wave counting number) and the accumulated AE energy. For example, the accumulated AE energy of the samples after 20 cycles of freezing-thawing increased by $350 \%$ and reached around $5.3 \times 106$ at the speed of $6.8 \times 104 / \mathrm{s}$ as shown in Figure 10(b). Both counting rate and accumulated energy were larger than that in the $A B$ stage. Due to the occurrence of cracking, the peak strength was reached at the end of this stage (line $\mathrm{C}$ ).

In the dropping stage (CD), the counting rates of all samples suddenly increased to a rather large value when the strain rapidly decreased at the end of this stage. For example, the counting rate of the samples after 20 freezing-thawing cycles rapidly increased to the maximum value of $62 \times 103 / \mathrm{s}$; the accumulated AE energy sharply increased to $1.1 \times 107$ with the maximum increasing rate of $1.4 \times 105 / \mathrm{s}$. This observation is consistent with the result in Figure 8 where in the $\mathrm{CD}$ stage, the major fracture occurred. The instant development of major through crack caused the sudden drop of the strain and the rapid increases in these two $\mathrm{AE}$ parameters.

In the deformation stage (DE), the strain has a second drop at around $300 \mathrm{~s}$. From line D to the second drop, the decrease in the AE parameters was significantly slower than that in the CD stage. Subsequently, these two parameters of all the samples significantly increased. This increasing rate was lower than that when the first drop occurred at line D. For example, the counting rate of the samples after 20 cycles of freezing-thawing cycles increased from $2 \times 103 / \mathrm{s}$ to $31 \times 103 / \mathrm{s}$. This result indicated that the movement of broken particles and the initiation of extra cracks that propagated from the major crack inside the samples were the main reason to dissipate the energy. To summarize, in the final stage of minimal cracking in samples, the counting rate and the AE energy both had much less value than that in stage $\mathrm{BC}$ and stage $\mathrm{CD}$ where major cracking occurred.

4.2. Comparison of Counting Rates. As shown in Figure 10, the counting rates of the samples after $0,20,40$, and 60 freezing-thawing cycles had similar variation trends in the $\mathrm{AB}$ and $\mathrm{BC}$ stages. They gradually and slowly increased during this period. The counting rates of samples after 80 freezing-thawing cycles had a dispersed distribution before the axial stress reached the peak strength. They were also much higher than that after other freezing-thawing cycles, indicating that the cracking extent is much higher in samples under 80 freezing-thawing cycles compared to other cycles.

When the stress was suddenly dropped (line C), the counting rates of all samples were significantly increased to 


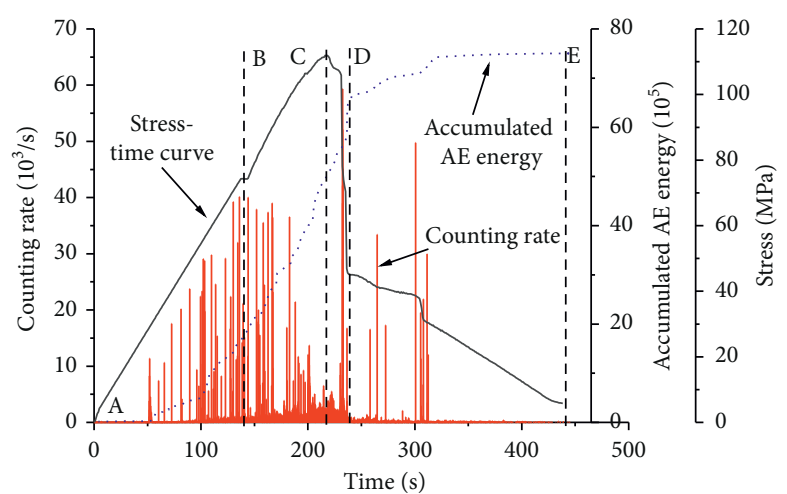

(a)

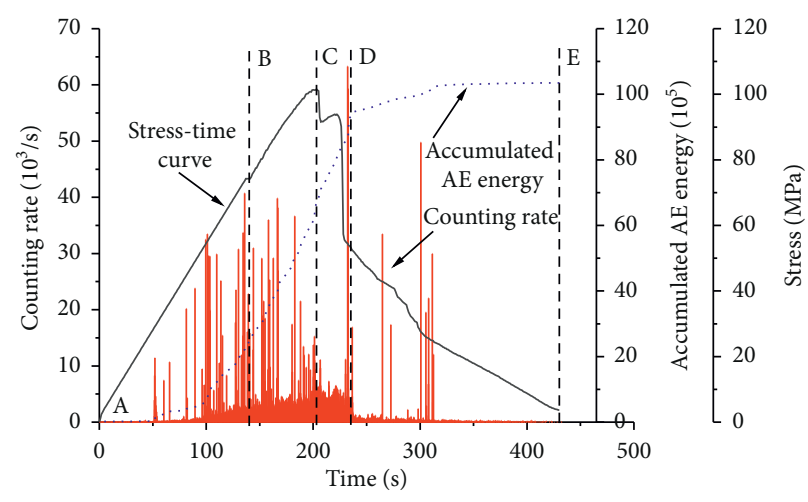

(c)

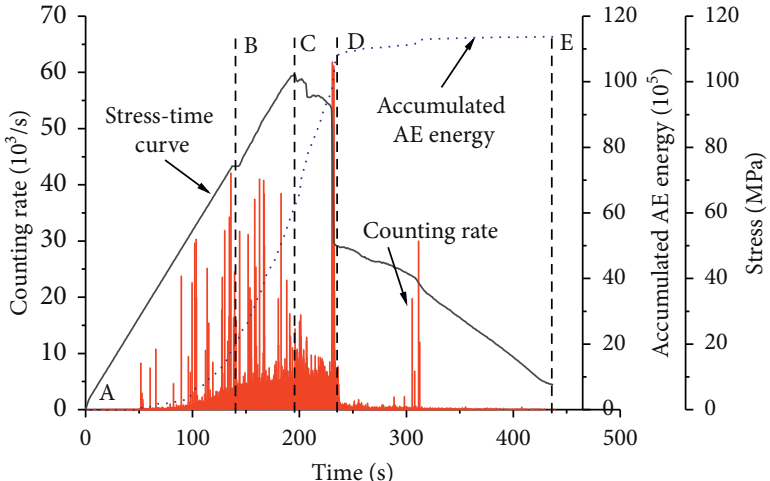

(b)

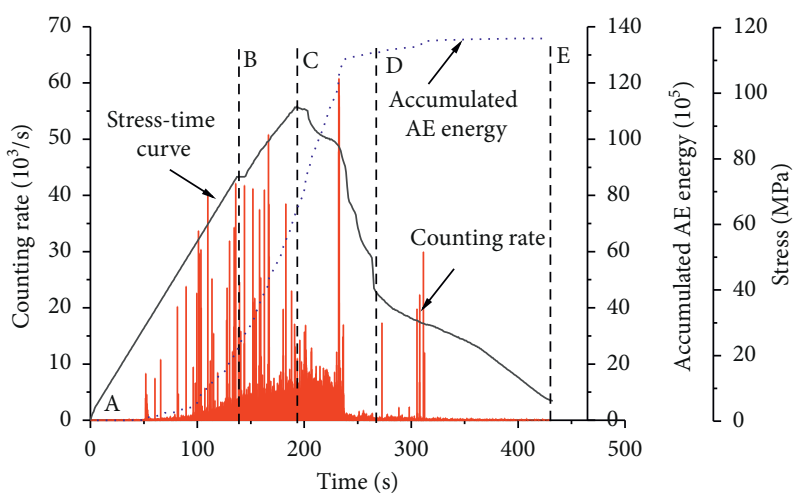

(d)

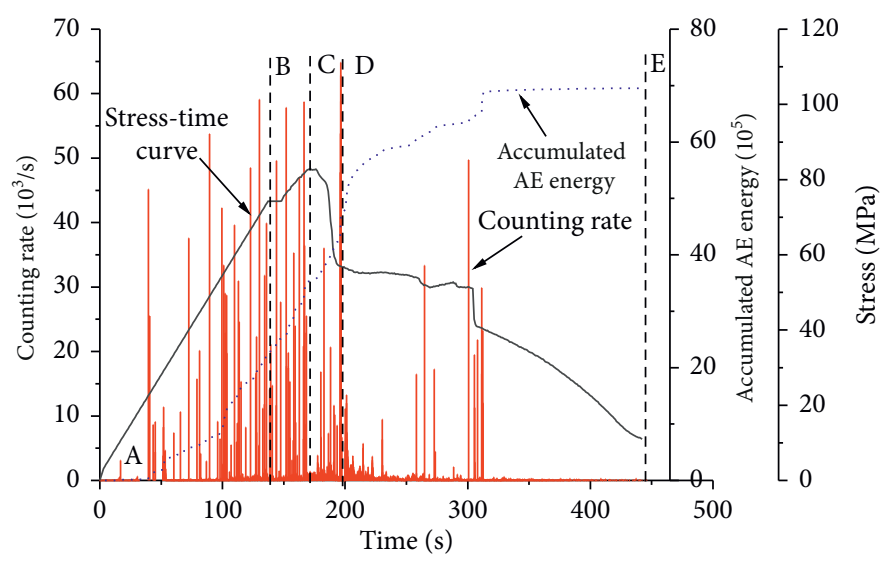

(e)

FIGURE 10: The counting rate and the accumulated AE energy of samples after (a) 0, (b) 20, (c) 40, (d) 60, and (e) 80 freezing-thawing cycles.

the maximum value and then rapidly decreased to a rather low value. This increase is due to the occurrence of through shear crack, as shown in Figure 6. On the occurrence of the second drop of stress, the counting rates increased again to a value that was lower than the maximum. Also, the average value of the counting rate increased with the number of freezing-thawing cycles. This increase might be because increasing cycles caused more initial microcracks, resulting in the higher counting rates in the early stage $(A B$ and $B C)$. The increase was more significant in the samples after 60-80 freezing-thawing cycles. This result is in agreement with that in Section 3.2 during the axial unloading tests and with that in other studies $[20,36]$.
4.3. Comparison of Accumulated AE Energy. The curves of accumulated AE energy of the samples consisted of three stages: the initiation stage, the sudden increasing stage, and the flat stage. The accumulated AE energy first increased then decreased with the increasing freezing-thawing cycles. The cracking caused by frost heave forces became more severe as more freezing-thawing cycles were conducted on the samples. Thus, the accumulated AE energy first increased within the first 60 cycles of freezing-thawing. When the number of cycles reached the threshold between 60 and 80, as discussed in Sections 3.1 and 3.2, the main damage could be caused by the freezing-thawing damage rather than the triaxial unloading condition. Thus, the energy could have 
been dissipated before the axial unloading test and AE test (similar to the analysis on the CD stage in Figure 8). This may be the reason why the accumulated AE energy of samples after 80 freezing-thawing cycles was lower than that of the samples after 60 cycles.

For each freezing-thawing cycle, we also observed all the accumulated AE energy of samples had a maximum increasing rate when the counting rate reached the maximum with the formation of through shear crack. This result is consistent with that in other studies such as Li et al. [21], who found that the accumulated energy released quickly when rock sample approached to its failure state. The increasing rate of $\mathrm{AE}$ energy may be potentially used as an index to identify the big rock fracture.

4.4. Implications. The potential risk of excavation of highly stressed, hard, brittle rock mass is the energy release and the rock damage in the forms of spalling and strain burst. It was reported that severe strain burst occurred along a considerable length of tunnel section, and energy changes were monitored during tunnel excavation of the China Jinping II hydropower station project $[37,38]$. It is thus important to develop a technique to monitor the damage development process and amount of released energy for the identification of damage occurrence. This study shows that the $\mathrm{AE}$ characteristics of sandstone samples matched well with the key stages of the measured axial stress-strain curves and the deformation modulus variation with confining pressure. The counting rates and accumulated AE energy could be thus potentially used to characterize the rock energy development process, quantify rock burst intensity, and identify the key damage state during the tunneling engineering process. The failure mechanism of rock burst has also been better understood in this study. The rock tunneling support, the safety operation of mining, and underground engineering with great mining depth could be better designed. Future study can be performed to explore the influence of cracking direction and $\mathrm{AE}$ sensor distribution on the energy and damage identification efficiency.

Most of the existing studies $[10-12,16]$ focus on the understanding of damage caused by the freezing-thawing cycles and some of them $[3,4,13,15]$ examine the dynamic rock characteristics under triaxial unloading tests but without freezing-thawing treatments. Thus, our study becomes one of the first attempts to comprehensively understand the damage behaviors of the tunneling sandstones in cold regions, where both freezing-thawing and unloading treatments could occur. In addition, due to the proper arrangement of $\mathrm{AE}$ sensors on samples, the $\mathrm{AE}$ technique was successfully used to monitor the counting rate and the accumulated AE energy during the whole period of the unloading tests. The macrocracking and microcracking observations, stress-strain curves, and deformation modulus match well with the AE characteristics. Although AE techniques have widely been applied to understand the rock mechanics under true-triaxial conditions, our study is one of the most comprehensive studies that include freezingthawing test, triaxial unloading test, AE test, SEM test, stress- strain measurement, and external surface observations to deepen the understanding of the rock failure process of tunneling rocks. Thus, our research results could bring new insights to the tunneling rock characteristics and their deterioration during freezing-thawing and triaxial unloading process as well as the potential application of AE technique in monitoring the critical damage stages during the tunneling engineering process.

\section{Conclusions}

In order to understand the damage characteristics of sandstone subjected to stress and energy release during the excavation in cold region, this paper first investigates the mechanical and AE characteristics of representative sandstone samples that were collected from the field and then subjected to different freezing-thawing cycles and triaxial unloading test and $\mathrm{AE}$ test.

The freezing-thawing treatment with moderate freezingthawing treatment (in this test, less than 60 freezing-thawing cycles with the highest and lowest temperature of $20^{\circ} \mathrm{C}$ and $-30^{\circ} \mathrm{C}$ ) could have much less damage to the samples compared to the triaxial unloading condition. The latter condition could induce cracks in samples, such as intercrystalline crack, transcrystalline crack, and intracrystalline crack, even when they were not under freezing-thawing treatment.

After the freezing-thawing treatments, the cracking effect on the samples due to the increase of axial compression value could outweigh the resistance effect caused by the decrease of confining pressure. More cracks could be unclosed under less confining pressure. For the samples under higher freezing-thawing cycles, more cracks were produced. These cracks were not closed under small confining pressure during the triaxial test, causing weaker mechanical properties of samples, i.e., less peak strength and less deformation modulus. A shear failure occurred while loading axial compression and releasing the confining pressure. The damage was more severe when the samples were subject to more freezing-thawing treatments before the triaxial test.

When the number of freezing-thawing cycles exceeded a certain threshold (between 60 and 80 in this study), the freezing-thawing treatment would cause a significant deterioration on the mechanical properties of the sandstone samples. The AE characteristics regarding counting rate and accumulated AE energy were consistent with the key stages of the measured axial stress-strain curves and the deformation modulus variation. They can be potentially utilized to quantify the released energy of rock cracking and identify the critical damage phases during the tunneling engineering process.

\section{Data Availability}

No data were used to support this study.

\section{Conflicts of Interest}

The authors declare that there are no conflicts of interest regarding the publication of this paper. 


\section{Acknowledgments}

This work was supported by the National Natural Science Foundation of China (grant nos. 51409122 and 51878249) and the Natural Science Foundation of Zhejiang Province (grant no. LQ12E08004).

\section{References}

[1] S.-H. Chang and C.-I. Lee, "Estimation of cracking and damage mechanisms in rock under triaxial compression by moment tensor analysis of acoustic emission," International Journal of Rock Mechanics and Mining Sciences, vol. 41, no. 7, pp. 1069-1086, 2004.

[2] H. Wang, A. Dyskin, P. Dight, E. Pasternak, and A. Hsieh, "Review of unloading tests of dynamic rock failure in compression," Engineering Fracture Mechanics, vol. 225, 2019.

[3] K. Peng, J. Zhou, Q. Zou, J. Zhang, and F. Wu, "Effects of stress lower limit during cyclic loading and unloading on deformation characteristics of sandstones," Construction and Building Materials, vol. 217, pp. 202-215, 2019.

[4] R. Q. Huang and D. Huang, "Evolution of rock cracks under unloading condition," Rock Mechanics and Rock Engineering, vol. 47, no. 2, pp. 453-466, 2014.

[5] S. Wang, X. Li, J. Yao et al., "Experimental investigation of rock breakage by a conical pick and its application to nonexplosive mechanized mining in deep hard rock," International Journal of Rock Mechanics and Mining Sciences, vol. 122, Article ID 104063, 2019.

[6] Y. Zhang, X. Ding, S. Huang, Y. Qin, P. Li, and Y. Li, "Field measurement and numerical simulation of excavation damaged zone in a $2000 \mathrm{~m}$-deep cavern," Geomechanics and Engineering, vol. 16, no. 4, pp. 399-413, 2018.

[7] L.-T. Xie, P. Yan, W.-B. Lu, M. Chen, and G.-H. Wang, "Effects of strain energy adjustment: a case study of rock failure modes during deep tunnel excavation with different methods," KSCE Journal of Civil Engineering, vol. 22, no. 10, pp. 4143-4154, 2018.

[8] J. H. Yang, Q. H. Jiang, Q. B. Zhang, and J. Zhao, "Dynamic stress adjustment and rock damage during blasting excavation in a deep-buried circular tunnel," Tunnelling and Underground Space Technology, vol. 71, pp. 591-604, 2018.

[9] J. C. Zhang, W. Y. Xu, H. L. Wang, R. B. Wang, Q. X. Meng, and S. W. Du, "A coupled elastoplastic damage model for brittle rocks and its application in modelling underground excavation," International Journal of Rock Mechanics and Mining Sciences, vol. 84, pp. 130-141, 2016.

[10] J. L. Li, R. B. Kaunda, L. Y. Zhu, K. P. Zhou, and F. Gao, "Experimental study of the pore structure deterioration of sandstones under freeze-thaw cycles and chemical erosion," Advances in Civil Engineering, vol. 2019, Article ID 9687843, 12 pages, 2019.

[11] H. Liu, X. Yuan, and T. Xie, "A damage model for frost heaving pressure in circular rock tunnel under freezingthawing cycles," Tunnelling and Underground Space Technology, vol. 83, pp. 401-408, 2019.

[12] M. M. Arzanfudi and R. Al-Khoury, "Freezing-thawing of porous media: an extended finite element approach for soil freezing and thawing," Advances in Water Resources, vol. 119, pp. 210-226, 2018.

[13] A. Manouchehrian and M. Cai, "Simulation of unstable rock failure under unloading conditions," Canadian Geotechnical Journal, vol. 53, no. 1, pp. 22-34, 2016.
[14] M. C. He, J. L. Miao, and J. L. Feng, "Rock burst process of limestone and its acoustic emission characteristics under truetriaxial unloading conditions," International Journal of Rock Mechanics and Mining Sciences, vol. 47, no. 2, pp. 286-298, 2010.

[15] W. Zhu, W. Yang, X. Li, L. Xiang, and D. Yu, "Study on splitting failure in rock masses by simulation test, site monitoring and energy model," Tunnelling and Underground Space Technology, vol. 41, pp. 152-164, 2014.

[16] J. Yu, G. Fu, X. Chen, and X. Guo, "Experimental study on mechanical properties of sandstone after freezing-thawing cycles under triaxial confining pressure unloading," Chinese Journal of Rock and Mechanics and Engineering, vol. 34, no. 10, pp. 2001-2009, 2015, in Chinese.

[17] A. Rotem and J. Baruch, "Determining the load-time history of fibre composite materials by acoustic emission," Journal of Materials Science, vol. 9, no. 11, pp. 1789-1796, 1974.

[18] X. Sun, H. Xu, M. He, and F. Zhang, "Experimental investigation of the occurrence of rockburst in a rock specimen through infrared thermography and acoustic emission," International Journal of Rock Mechanics and Mining Sciences, vol. 93, no. 93, pp. 250-259, 2017.

[19] D. Lockner, "The role of acoustic emission in the study of rock fracture," International Journal of Rock Mechanics and Mining Sciences \& Geomechanics Abstracts, vol. 30, no. 7, pp. 883899, 1993.

[20] A. Carpinteri and G. Lacidogna, "Damage monitoring of an historical masonry building by the acoustic emission technique," Materials and Structures, vol. 39, no. 2, pp. 161-167, 2006.

[21] H. Li, Z. Dong, Z. Ouyang, B. Liu, W. Yuan, and H. Yin, "Experimental investigation on the deformability, ultrasonic wave propagation, and acoustic emission of rock salt under triaxial compression," Applied Sciences, vol. 9, no. 4, p. 635, 2019.

[22] F. Amann, P. Kaiser, E. A. Button, V. S. Gischig, and M. Blümel, "Experimental study of the brittle behavior of clay shale in rapid unconfined compression," Rock Mechanics and Rock Engineering, vol. 45, no. 1, pp. 21-33, 2012.

[23] S. J. D. Cox and P. G. Meredith, "Microcrack formation and material softening in rock measured by monitoring acoustic emissions," International Journal of Rock Mechanics and Mining Sciences \& Geomechanics Abstracts, vol. 30, no. 1, pp. 11-24, 1993.

[24] H. Fujii, Y. Saito, M. Tanaka, Y. Machijima, and T. Mori, "The AE characteristic in hard rock and soft rock specimens of compression failure using optical type AE sensor (FOD)," in Proceedings of the National Conference on Acoustical Emission, vol. 17, pp. 99-102, Kyoto, Japan, May 2009.

[25] B. Kong, E. Wang, Z. Li, X. Wang, J. Liu, and N. Li, "Fracture mechanical behavior of sandstone subjected to high-temperature treatment and its acoustic emission characteristics under uniaxial compression conditions," Rock Mechanics and Rock Engineering, vol. 49, no. 12, pp. 4911-4918, 2016.

[26] H. Zhang, D. Fu, H. Song et al., "Damage and fracture investigation of three-point bending notched sandstone beams by DIC and AE techniques," Rock Mechanics and Rock Engineering, vol. 48, no. 3, pp. 1297-1303, 2015.

[27] N. N. Sirdesai, T. Gupta, T. N. Singh, and P. G. Ranjith, "Studying the acoustic emission response of an Indian monumental sandstone under varying temperatures and strains," Construction and Building Materials, vol. 168, pp. 346-361, 2018.

[28] C. E. Fairhurst and J. A. Hudson, "Draft ISRM suggested method for the complete stress-strain curve for intact rock in 
uniaxial compression," International Journal of Rock Mechanics and Mining Sciences, vol. 36, no. 3, pp. 279-289, 1999.

[29] Y. Lu, L. Wang, Z. Li, and H. Sun, "Experimental study on the shear behavior of regular sandstone joints filled with cement grout," Rock Mechanics and Rock Engineering, vol. 50, no. 5, pp. 1321-1336, 2017.

[30] DL/T 5368, Code for Rock Tests of Hydroelectric and Water Conservancy Engineering, National Development and Reform Commission, People's Republic of China, Beijing, China, 2007.

[31] Z. Wu, H. S. Wong, C. Chen, and N. R. Buenfeld, "Anomalous water absorption in cement-based materials caused by drying shrinkage induced microcracks," Cement and Concrete Research, vol. 115, pp. 90-104, 2019.

[32] L. H. Wang, Z. R. Jiang, J. L. Li, K. Y. Tang, and J. Jin, "The bedding sandstone unloading mechanical properties experimental study in the freeze-thaw cycle condition," Journal of Glaciology and Geocryology, vol. 38, no. 4, pp. 1052-1058, 2016, in Chinese.

[33] Z. Wu, H. S. Wong, and N. R. Buenfeld, "Effect of confining pressure and microcracks on mass transport properties of concrete," Advances in Applied Ceramics, vol. 113, no. 8, pp. 485-495, 2014.

[34] J. A. Hudson, E. Liu, and S. Crampin, "The mechanical properties of materials with interconnected cracks and pores," Geophysical Journal International, vol. 124, no. 1, pp. 105-112, 1996.

[35] Q. Zou, Q. Li, T. Liu, X. Li, and Y. Liang, "Peak strength property of the pre-cracked similar material: implications for the application of hydraulic slotting in ECBM," Journal of Natural Gas Science and Engineering, vol. 37, pp. 106-115, 2017.

[36] X. Liu, H. Zhang, X. Wang et al., "Acoustic emission characteristics of graded loading intact and holey rock samples during the damage and failure process," Applied Sciences, vol. 9, no. 8, p. 1595, 2019.

[37] B.-R. Chen, X.-T. Feng, Q.-P. Li, R.-Z. Luo, and S. Li, "Rock burst intensity classification based on the radiated energy with damage intensity at Jinping II hydropower station, China," Rock Mechanics and Rock Engineering, vol. 48, no. 1, pp. 289-303, 2015.

[38] D. Y. Zhuang, K. Ma, C. Tang, Z. Z. Liang, and Z. W. Wang, "Microseismic monitoring of energy changes in deep tunnels during the TBM tunneling of the Jinping II hydropower station," Advances in Civil Engineering, vol. 2018, Article ID 5364628, 15 pages, 2018. 